\title{
Scaling Analysis on Pulsating Flame Spread over Liquids
}

\author{
Kozue Takahashi, ${ }^{1}$ Akihiko Ito, ${ }^{1}$ Yuji Kudo, ${ }^{1}$ Tadashi Konishi, ${ }^{2}$ and Kozo Saito ${ }^{3}$ \\ ${ }^{1}$ Department of Intelligent Machines and System Engineering, Hirosaki University, Hirosaki 036-8561, Japan \\ ${ }^{2}$ Department of Mechanical Engineering, Oita National College of Technology, Oita 879-0152, Japan \\ ${ }^{3}$ Department of Mechanical Engineering, University of Kentucky, Lexington, KY 40506, USA \\ Correspondence should be addressed to Akihiko Ito, aito@cc.hirosaki-u.ac.jp
}

Received 16 February 2008; Accepted 12 May 2008

Recommended by Adrian Schumpe

\begin{abstract}
Scaling analyses based on subsurface layer instability were performed to explore the role of three independent (surface tension, gravity, and viscosity) influences on the mechanism of pulsating flame spread under normal and microgravity conditions. These three influences form two independent pi-numbers: the Marangoni (Ma) number and Grashof (Gr) number, which include the characteristic length scale ratio (depth of subsurface circulation)/(horizontal length of preheated liquid surface). The Prandtl (Pr) number was introduced to compensate for the different thermal diffusivity and kinematic viscosity of different liquids. Also a nondimensional flame spread rate, $V / V_{D}(=V \delta / D$, where $\delta$ is the quenching distance and $D$ is the diffusivity of fuel vapor) was introduced. Using these nondimensional parameters, the flame spread mechanism was divided into two separate regimes: for the shallow liquid pool the nondimensional flame spread rate was correlated with $\left\{\mathrm{Gr}^{0.2} /(\mathrm{Ma} \cdot \mathrm{Pr})\right\}^{1.0}$, while for the deep liquid pool it was correlated with $\left\{\mathrm{Gr}^{0.2} /(\mathrm{Ma} \cdot \mathrm{Pr})\right\}^{1.5}$.
\end{abstract}

Copyright (C) 2008 Kozue Takahashi et al. This is an open access article distributed under the Creative Commons Attribution License, which permits unrestricted use, distribution, and reproduction in any medium, provided the original work is properly cited.

\section{Introduction}

Flame spread over liquids is one of our current interests, because of both its relevance to fire safety and our basic curiosity about its complex mechanism. A series of studies was performed to understand the flame spread mechanism on alcohols [1-12] and hydrocarbon fuels $[4,10]$. Based on these results, Glassman and Dryer [13] wrote a review that includes explanations of the mechanism of pulsating spread over subflash point liquids. According to Glassman and Dryer [13], pulsating flame spread could be a result of coupled gas-liquid phase convection effects, since it occurs only when subsurface liquid convection has been generated. Recently, Ross and Miller conducted flame spread experiments in microgravity on shallow liquid pools $[14,15]$ and on deep liquid pools [16]. Including these results for microgravity flame spread, Ross wrote a review in a book he edited [17] stating that the rate and frequency in pulsating flame spread depend on gravity, liquid pool depth, initial fuel temperature, gas flow rate, the kind of liquid, and so on, indicating that the mechanism of pulsating flame spread is not yet completely understood.
Over the past ten years, a series of experimental studies of flame spread over liquids has been conducted [14-29], creating a rich experimental database. With six different experimental techniques (laser sheet particle tracking, smoke tracing, single and dual wavelength holographic interferometry, infrared thermography, and high-speed photography), we measured the detailed thermal, fluid dynamic and chemical structures of both gas, and liquid phases near the flame's leading edge to understand the mechanism of pulsating flame spread [26-29]. We found a dual pulsation structure for flame pulsation, consisting of a main pulsation of about 0.5 to $1 \mathrm{~Hz}$, and a subpulsation of about 5 to $10 \mathrm{~Hz}$ [29]. The main pulsation generated and eliminated a cold temperature valley in the liquid surface ahead of the flame [28]. Based on these experimental data, we proposed a pulsating flame spread model [28] involving subsurface layer circulation and a surface wave. Figure 1 shows a series of photographs of a pulsating flame and schematic side views of liquid and gas flow structures for the four steps of the cycle (a)-(d). Step (a) is the onset of pulsation. There is little flow in the liquid phase, while there is air flow that is induced by buoyancy ahead of the flame leading edge. The flame 

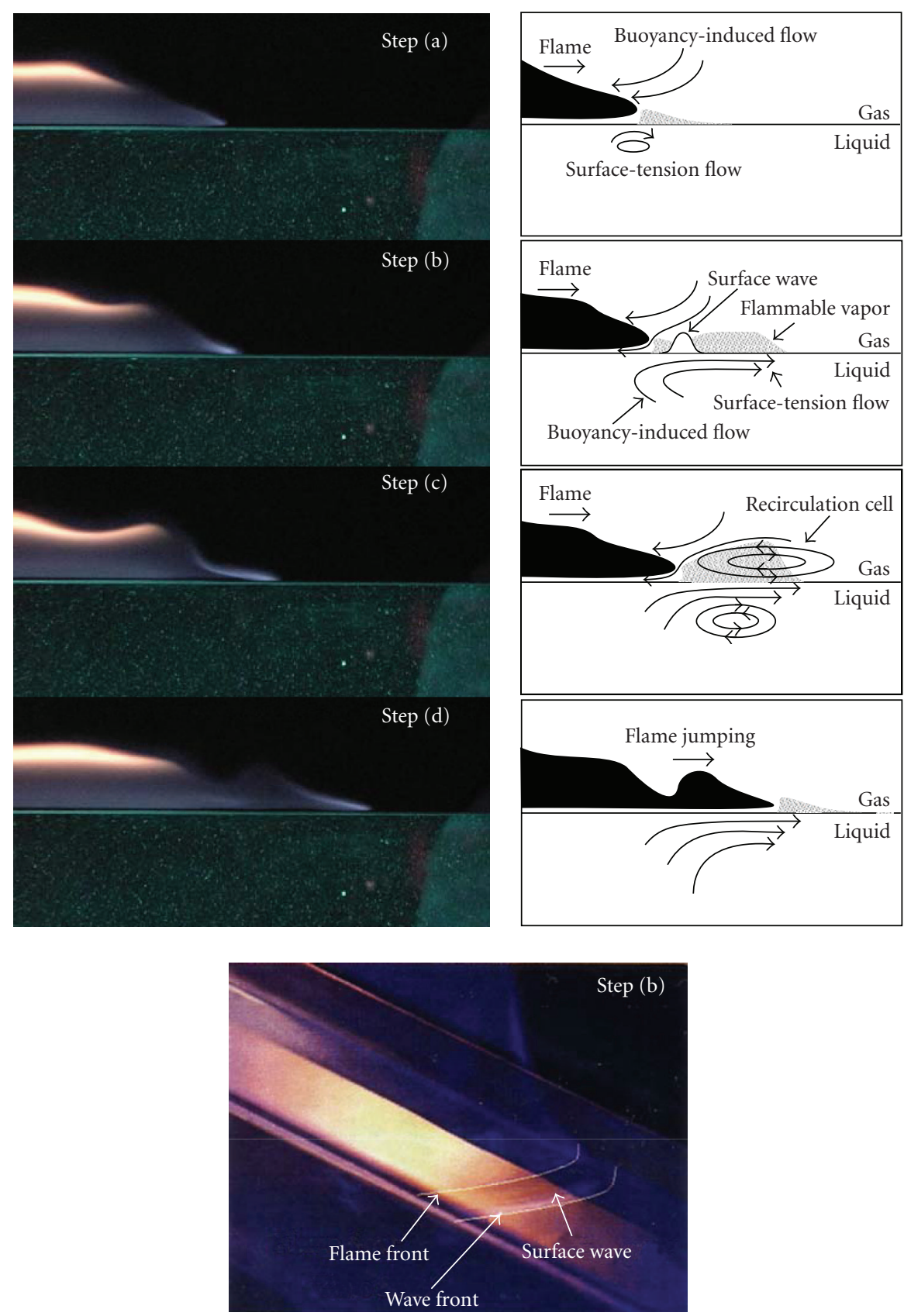

FIGURE 1: Step in a single cycle of pulsating flame spread and surface wave in step (b) [29].

spreads slowly in this crawl phase of the pulsation cycle. Step (b) is the formation of a cold temperature valley. Rapid interfacial flow develops due to thermocapillarity toward the upstream direction and produces convective motion inside the bulk liquid and also a small-scale wave on the liquid surface. A cold temperature valley where the minimum temperature is below the flash point exists ahead of the flame leading edge. Step (c) is fuel vapor buildup. Some of the warm liquid flows on the surface ahead of the flame, the upstream liquid fuel surface temperature rises above the flash point and then the cold temperature valley disappears. The liquid fuel evaporates and diffuses into the recirculation cell. The fuel vapor in the cell accumulates with time and reaches a nearly uniform flammable concentration. Step (d) is flame jumping. When the height of the flammable lean limit exceeds that of the quenching layer, the flame jumps forward to the flammable layer. In the process of jumping, the combusting gases expand thermally and destroy the recirculation cell. The flame front nearly stops at the end of the flammable layer and then begins to spread slowly [returns to step (a)] and the cycle repeats itself.

To benefit from all these experimental and numerical studies both under normal gravity and microgravity and to update the theory of flame spread over liquids formulated 
by Williams [30], we conducted stability based on the basic reference [31] and scaling analyses on these results in the hope of finding a unified theoretical framework within which to relate them [32-34]. Our instability analysis was focused on the liquid subsurface layer ahead of a flame's leading edge, where a surface wave is initiated and a cold temperature valley is created. The four pi-numbers, Marangoni (Ma) number, Grashof (Gr) number, Weber (We) number, and Froude (Fr) number, and a characteristic length scale ratio $\left(h_{T} / L\right)$ were introduced for scaling analysis. The characteristic length scale ratio, $h_{T} / L$ consists of a characteristic thermal fluid length in the liquid surface, and a subsurface liquid circulation (or thermal structure) depth both created by the spreading flame. Figure 2 shows thermal and flow characteristic depths $h_{T}$ and $h_{F}$, and thermal characteristic length $L$, determined from a shadowgraph image and a particle-track laser-sheet image [34].

William used the liquid pool depth as an approximation for the characteristic length in his flame spread theory and pointed out that it is both possible and desirable to pursue more careful analysis to obtain improved estimates of spread rate using an appropriate characteristic length [30]. In this study, we experimentally measured both thermal and fluid characteristic lengths and depths and improved our previous instability and scaling analyses using these results. We propose a new formula for the nondimensional flame spread rate as a function of $\mathrm{Gr}^{0.2} /(\mathrm{Ma} \cdot \mathrm{Pr})$ on both deep and shallow pools, and also we discuss the effect of gravity on pulsating flame spread.

\section{Theoretical Analysis}

\subsection{Basic Equation}

Our objective is to study the instability of laminar subsurface layer flow ahead of a spreading flame. The temperature coefficient of surface tension and other physical properties are treated as constants. Our instability analysis is based on the previous study [31-34]. A schematic of subsurface layer flow is shown in Figure 3. The depth of subsurface layer [18] that we conduct our analysis is an order of $2 \mathrm{~mm}$ (very thin); we use the fully developed flow assumption. All symbols used are defined in the nomenclature section. The liquid temperature just ahead of the flame leading edge is higher than the bulk liquid temperature because the hightemperature liquid generated by the flame moves in the upstream direction due to surface tension. The continuity and momentum equations for the subsurface layer can be, respectively, expressed as

$$
\begin{gathered}
h_{t}+(h u)_{x}=0 \\
(h u)_{t}+\left(\int_{0}^{h} U^{2} d y+\frac{1}{2} g h^{2}\right)_{x}+\left(\frac{\sigma k^{2} \delta h}{\rho}\right)_{x}=\frac{1}{\rho}\left(\tau_{i}-\tau_{b}\right)
\end{gathered}
$$

The third term on the LHS in (2) is due to surface tension, where $\delta=A \exp i k(x-c t)$ is the expression for the surface wave, $k(\equiv 2 \pi / \lambda)$ is the wave number, $\lambda$ is the wavelength, $c$ is the wave velocity, and all other symbols are defined in the nomenclature section. In $(2), \tau_{i}$ is the surface shear stress due to the Marangoni effect and is expressed as

$$
\tau_{i}=\frac{\partial \sigma}{\partial x}=\sigma_{T} \frac{\partial T}{\partial x}, \quad \sigma_{T} \equiv \frac{d \sigma}{d T} .
$$

If the momentum displacement thickness: $\beta\left(\equiv \int_{0}^{h} U^{2} d y / u^{2} h\right)$ and the continuity equation, (1), are substituted into (2), we can obtain the following equation:

$$
\begin{aligned}
h u_{t}+ & (2 \beta-1) h u u_{x}+(\beta-1) u^{2} h_{x}+\beta_{x} u^{2} h+g h h_{x} \\
& +\frac{\sigma k^{2}}{\rho}\left(\delta_{x} h+\delta h_{x}\right) \\
= & \frac{1}{\rho}\left(\tau_{i}-\tau_{b}\right) .
\end{aligned}
$$

The perturbation at the gas-liquid interface is very small and the independent variables $(u, h, \tau)$ are expressed as

$$
\begin{array}{cl}
u=\bar{u}+u^{\prime}, & \tau_{b}=\bar{\tau}_{b}+\tau_{b}^{\prime}, \\
h=\bar{h}+\delta, & \tau_{i}=\bar{\tau}_{i}+\tau_{i}^{\prime},
\end{array}
$$

where the superscripts bar and prime indicate time-averaged and perturbation quantities, respectively. If the velocity remains similar on perturbation, then $\beta=\bar{\beta}$. With the substitution of (5) and (1) into (4), and if the velocity is fully developed, $\bar{u}_{x}=\bar{h}_{x}=0, \bar{\tau}_{i}=0, \bar{\tau}_{b}=0$, and the higherorder perturbation terms are negligible; the continuity and momentum equations can then, respectively, be written as

$$
\begin{gathered}
\delta_{t}+\bar{u} \delta_{x}+\bar{h} u_{x}^{\prime}=0, \\
u_{t}^{\prime}+(2 \bar{\beta}-1) \bar{u} u_{x}^{\prime}+(\bar{\beta}-1) \bar{u}^{2} \frac{\delta_{x}}{h}+g \delta x+\frac{\sigma k^{2}}{\rho} \delta_{x}=\frac{1}{\rho \bar{h}}\left(\tau_{i}^{\prime}-\tau_{b}^{\prime}\right) .
\end{gathered}
$$

If $\bar{\tau}_{b}^{\prime}$ is small, the deviation from the time-averaged value $\bar{\tau}_{b}=\left.\mu(d \bar{u} / d y)\right|_{y=0}=3 \mu(\bar{u} / \bar{h})$, which may be written as

$$
\tau_{b}^{\prime}=\tau_{b}-\bar{\tau}_{b} \fallingdotseq 3 \mu\left(\frac{u}{h}-\frac{\bar{u}}{\bar{h}}\right) \fallingdotseq 3 \mu \frac{u^{\prime}}{\bar{h}} .
$$

This implies that no heat is stored in the subsurface layer. All the heat is transferred at the gas-1iquid interface. If the flow is laminar, $\bar{T}_{i}=\bar{T}_{b}-\alpha\left(q_{i} / \lambda_{l}\right) \bar{h}$, where $\bar{T}_{b}$ is the time-averaged temperature in the liquid, $\lambda_{l}$ is the thermal conductivity of the liquid, and $\alpha$ is the heat release factor (a positive sign indicates that heat is released from the surface to the gas phase, negative indicates that heat is absorbed at the surface). If the perturbation of the surface temperature is very small, then

$$
T_{i}=\bar{T}_{b}-\alpha \frac{q_{i}}{\lambda_{l}} h=\bar{T}_{b}-\alpha \frac{q_{i}}{\lambda_{l}}(\bar{h}+\delta) .
$$

Differentiating $T_{i}$ with respect to $x$, and substituting into (3), we obtain

$$
\tau_{i}^{\prime}=-\alpha \frac{q_{i}}{\lambda_{l}} \sigma_{T} \delta_{x} .
$$



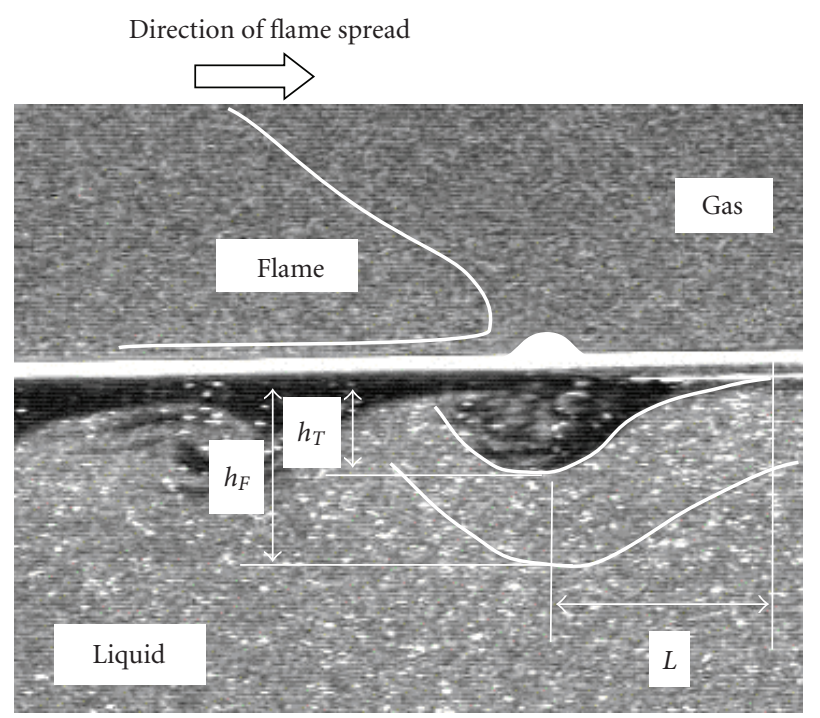

FIgURE 2: A shadowgraph and a particle laser-sheet image defining thermal characteristic length, $L$, and thermal and flow depth, $h_{T}$ and $h_{F}$, of subsurface layer circulation (fuel is n-butanol, $H=50 \mathrm{~mm}$ and the initial fuel temperature $=23.2^{\circ} \mathrm{C}$ ).

By substituting (8) and (10) into (7) and differentiating with respect to $x$ and using (6) to eliminate $u$, we can obtain the following wave equation:

$$
\left(\frac{\partial}{\partial t}+C_{+} \frac{\partial}{\partial x}\right)\left(\frac{\partial}{\partial t}+C_{-} \frac{\partial}{\partial x}\right) \delta+\frac{3 \mu}{\rho \bar{h}^{2}}\left(\frac{\partial}{\partial t}+C_{0} \frac{\partial}{\partial x}\right) \delta=0
$$

where

$$
\begin{aligned}
& C_{ \pm}=\bar{\beta} \bar{u} \pm \sqrt{(\bar{\beta}-1) \bar{\beta} \bar{u}^{2}+g \bar{h}+\sigma k^{2} \frac{\bar{h}}{-\rho}+\alpha \sigma_{T} \frac{q_{i}}{\rho \lambda_{l}}}, \\
& C_{0}=\bar{u} .
\end{aligned}
$$

The first term on the LHS of (11) represents the dynamic wave, where $C_{+}$and $C_{-}$, respectively, represent the forward and reverse propagation velocities. The second term on the LHS of (11) represents the kinematic wave, where $C_{0}$ is the propagation velocity in the direction of flow. Equation (11) represents the surface wave as a linear combination of the dynamic wave and the kinematic wave. The Marangoni effect appears in the $C_{ \pm}$term in the dynamic wave expression.

If the surface perturbation is expressed as $\delta=$ $a \exp i(k x-\omega t)$, we obtain the following equation from (11):

$$
\left(\omega-k C_{-}\right)\left(\omega-k C_{+}\right)+i \frac{3 \mu}{\rho \bar{h}^{2}}\left(\omega-k C_{0}\right)=0 .
$$

Hence, $\omega$ may be approximated as

$$
\omega \cong\left\{k C_{+}-\frac{i\left(3 \mu / \rho \bar{h}^{2}\right)\left(C_{+}-C_{0}\right)}{\left(C_{+}-C_{-}\right)}+k C_{-}-\frac{i\left(3 \mu / \rho \bar{h}^{2}\right)\left(C_{0}-C_{-}\right)}{\left(C_{+}-C_{-}\right)}\right\} .
$$

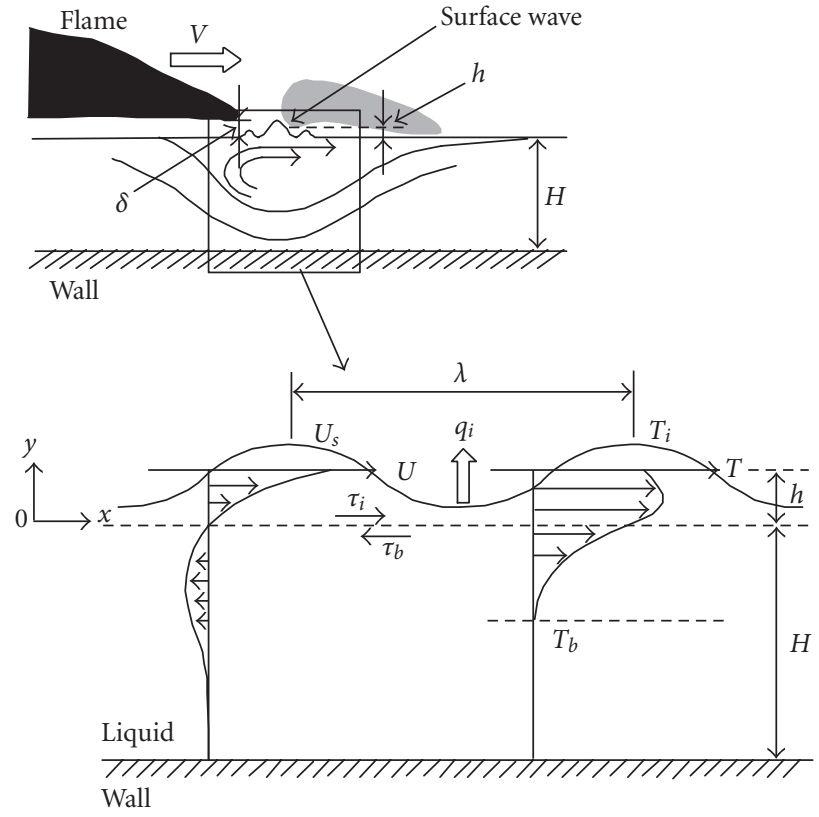

FIgURE 3: Subsurface layer flow model and symbols.

If $I_{m}(\omega)>0$, the dynamic wave is unstable, resulting in $C_{0} \geqq C_{+}$. This then becomes a neutrally stable condition, $C_{0}=C_{+}$. The following equation describes the generation of the surface wave:

$$
(1-\bar{\beta}) \bar{u}^{2}=g \bar{h}+\sigma k^{2} \frac{\bar{h}}{\rho}+\alpha \sigma_{T} \frac{q_{i}}{\rho \lambda_{l}} .
$$

If the local liquid velocity is defined as $U=\left(U_{S} / \bar{h}^{2}\right) y^{2}(0 \leq$ $y \leq \bar{h})$, the liquid volumetric flow rate per unit width of the tray is $\Gamma=\int_{0}^{\bar{h}} U d y=(1 / 3) U_{S} \bar{h}$, the average liquid velocity is $\bar{u}=\int_{0}^{\bar{h}} U d y / \bar{h}=(1 / 3) U_{S}$, the momentum displacement thickness is $\beta=\int_{0}^{\bar{h}} U^{2} d y / u^{2} \bar{h}=9 / 5$, and the heat release factor is $\alpha=1$. Equation (15) can be rewritten as

$$
-3^{1 / 3} \frac{4}{15} \Gamma_{\mathrm{cr}}^{4 / 3}-3^{1 / 3}\left(g+\frac{\sigma k^{2}}{\rho}\right) \Gamma_{\mathrm{cr}}^{1 / 3}=\frac{\sigma_{T}}{\rho \lambda_{l}} q_{i},
$$

where $\Gamma_{\mathrm{cr}}$ is the critical flow rate required for surface wave to occur.

\subsection{Conditions for Generation of a Surface Wave}

The neutral stable line obtained from (16) is shown in Figure 4 for three different wavelengths into a parameter. The following values are used for calculation: $\sigma=24.17 \times$ $10^{-3} \mathrm{~N} / \mathrm{m}, \sigma_{T}=-8.16 \times 10^{-5} \mathrm{~N} / \mathrm{m} \cdot \mathrm{K}, \rho=809 \mathrm{~kg} / \mathrm{m}^{3}, \lambda_{i}=$ $149 \times 10^{-3} \mathrm{~W} / \mathrm{m} \cdot \mathrm{K}$, and $\alpha=1$. As the hot liquid flows ahead of the flame leading edge due to Marangoni force, the liquid surface temperature is higher than the gas phase temperature. The $q_{i}$ in horizontal in Figure 4 is positive for heat release from the liquid surface to the gas phase. 
The area above the neutral stable line in Figure 4 shows an unstable region, which corresponds to the region, where the surface wave is generated. Theoretical considerations show the following: (1) shorter wavelength perturbations can easily develop into a surface wave, (2) the liquid surface is more stable as the heat flux from the liquid surface to the gas phase increases.

In experiments, uniform flame spread changes to pulsation at a certain temperature below the flash point. The Marangoni force is proportional to the temperature difference between the hot zone underneath the flame leading edge and the bulk liquid temperature. When the liquid bulk temperature is lower, the Marangoni force is greater. This may lead to a subsurface flow rate increase and the generation of a surface wave.

\subsection{The Nondimensional Parameter}

An overall energy balance and an overall momentum balance for the subsurface layer, respectively, produce the following:

$$
\begin{gathered}
q_{i}=\frac{\lambda_{l} \Delta T}{\alpha h_{T}}, \\
\mu \frac{U_{S}}{h_{F}}=\sigma_{T} \frac{\Delta T}{L}+\beta \rho g \frac{\Delta T}{L} h_{T}^{2},
\end{gathered}
$$

where $L$ and $h_{T}$ are the thermal characteristic length and depth and $h_{F}$ is the flow characteristic depth of the subsurface layer circulation defined in Figure 2. The characteristic depth scale ratio is expressed as

$$
\gamma=\frac{h_{F}}{h_{T}} .
$$

The difference between the thermal characteristic depth and flow depth is discussed in Section 4.2. Using (17) and (18), the following nondimensional parameters are introduced:

$$
\begin{aligned}
\mathrm{Fr} & \equiv \frac{\sqrt{\gamma} \sigma_{T} \Delta T}{2 \mu \sqrt{g}} \frac{1}{\sqrt{h_{T}}} \frac{h_{T}}{L}, \\
\mathrm{We} & \equiv \frac{\gamma^{2} \rho \sigma_{T}^{2} \Delta T^{2}}{4 \mu^{2} \sigma} \lambda\left(\frac{h_{T}}{L}\right)^{2}, \\
\mathrm{Ma} & \equiv \frac{\gamma^{2} \rho \sigma_{T} \Delta T}{4 \mu^{2}} h_{T}\left(\frac{h_{T}}{L}\right)^{2}, \\
\mathrm{Gr} & \equiv \frac{\gamma^{2} \beta^{2} \rho^{3} g^{2} \Delta T}{4 \mu^{2} \sigma_{T}} h_{T}^{5}\left(\frac{h_{T}}{L}\right)^{2} .
\end{aligned}
$$

Using (19), (20), (21), and (22), (15) can be rewritten in this nondimensional form:

$$
1-\bar{\beta}=\frac{1}{\mathrm{Fr}^{2}}+4 \pi^{2} \frac{\bar{h}}{\lambda} \frac{1}{\mathrm{We}}-\left\{\frac{1}{\sqrt{\mathrm{Ma}}}+\frac{1}{\sqrt{\mathrm{Gr}}}\right\}^{2} .
$$

Equations (19), (20), (21), and (22), all having the characteristic length scale ratio in their expressions, describe the generation of a liquid surface wave and its propagation. Therefore, these four equations may predict the onset of flame pulsation and subsequent pulsating flame spread

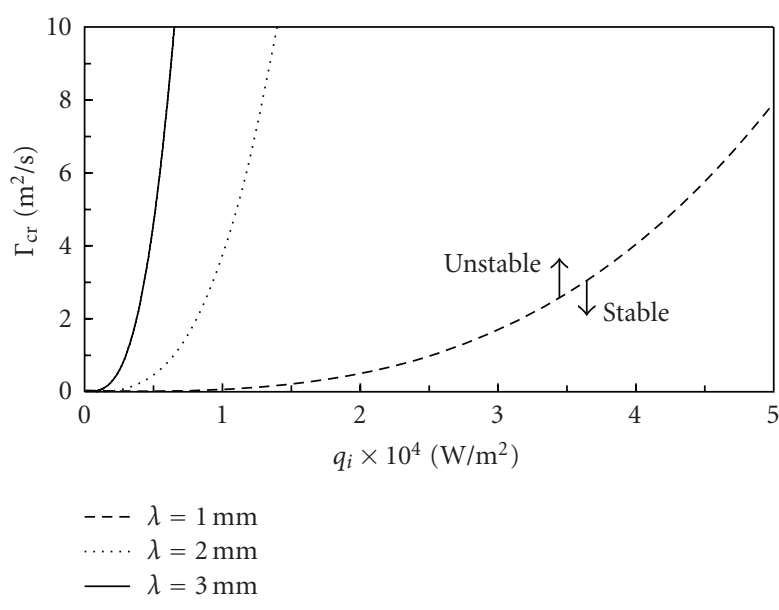

FIgURE 4: The neutral stable line.

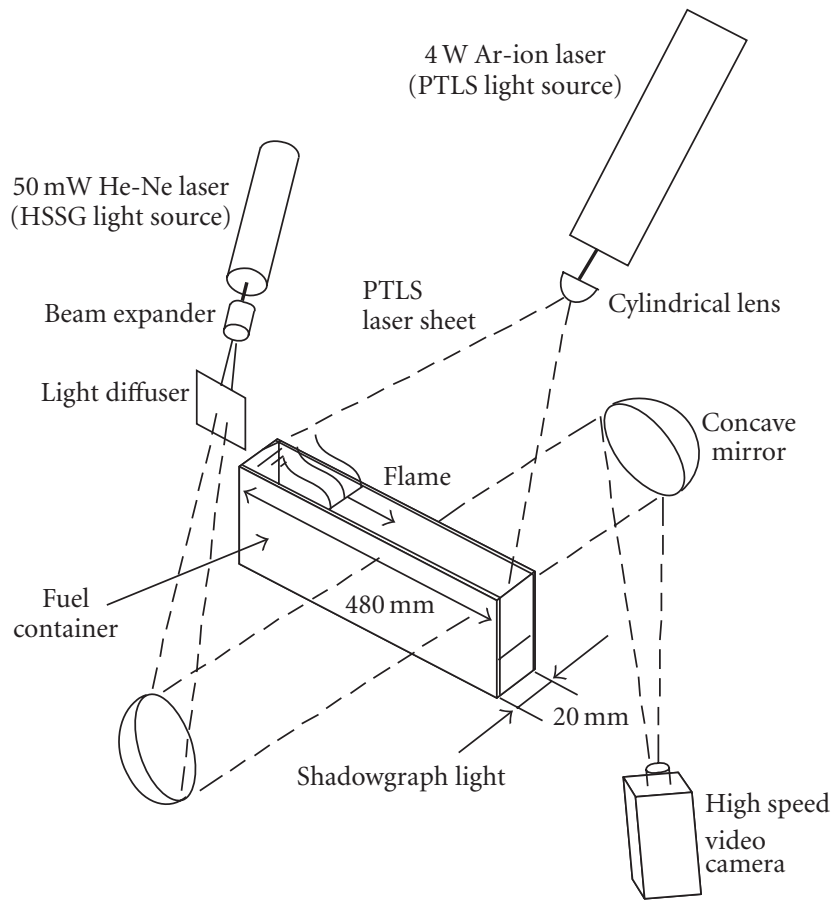

FIgURE 5: Experimental apparatus.

over liquids. These predictions will be validated by other researchers' experimental data as well as our own past and future experiments.

\section{Experimental Apparatus and Method}

\subsection{Normal Gravity Experiments}

A schematic of the experimental apparatus is shown in Figure 5, including a high sensitivity shadowgraph (HSSG) and a particle-track laser-sheet (PTLS) flow visualization apparatus.

The fuel container is $480 \mathrm{~mm}$ long $\times 20 \mathrm{~mm}$ wide $\times$ seven different heights $(2,5,7,10,15,20$, and $50 \mathrm{~mm})$. Its bottom 


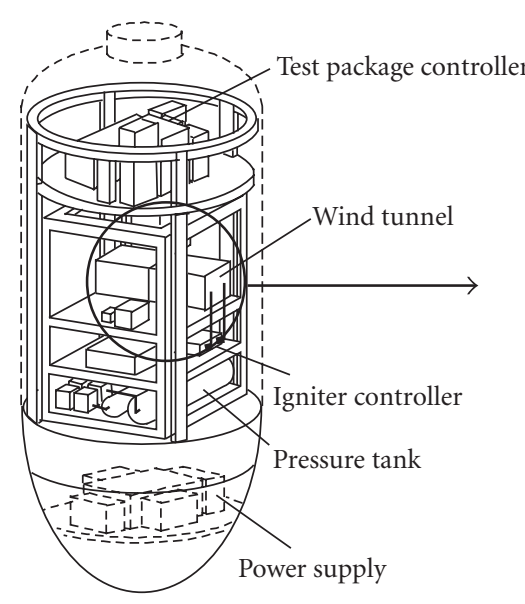

(a) Test package

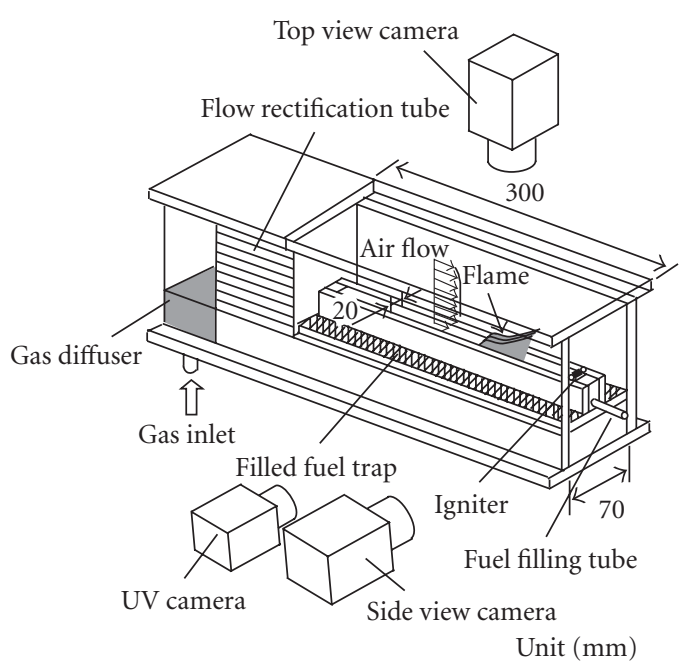

(b) Wind tunnel

FIGURE 6: Experimental apparatus for a shallow liquid pool in microgravity.

is brass and its sides Pyrex. Both n-propanol and n-butanol were used as test fuels. The container was filled to its limit in order to eliminate any meniscus. A small pilot flame at one end of the tray initiated the flame that propagated to the other end. The flame spread was recorded by a digital video camera. The flame spread rate was measured from the recorded digital image.

Temperature structures created in the liquid were visualized by our specially designed high sensitivity shadowgraph (HSSG) [34], which measures the refraction of a beam when it passes across the liquid. The $50 \mathrm{~mW} \mathrm{He-Ne} \mathrm{laser}$ beam passes through a tracing paper and is changed into scattered light in order to remove any distortion from the shadowgraph. For flow visualization and velocity measurement in the liquid phase, a particle-track laser-sheet (PTLS) technique was used [28], with a high-speed video camera (125 frames/sec, $20 \mathrm{~mm} \times 20 \mathrm{~mm}$ field of view). PTLS can measure profiles of both streamlines and the twodimensional velocity with significantly fewer particles and nearly instantaneously. Using a $4 \mathrm{~W}$ argon-ion laser beam and a cylindrical lens, we established a thin laser sheet with an approximately 35 degree opening angle. The fuel was seeded in advance with hollow glass particles ( $5 \mu \mathrm{m}$ average diameter, $1.02 \mathrm{~g} / \mathrm{cm}^{3}$ density) for visualization of the flow field in the liquid fuel.

\subsection{Microgravity Experiments}

The microgravity experiments were conducted using the 4.5-second drop tower facility at Microgravity Laboratory of Japan (MGLAB). A 4.5-second period of microgravity is obtained by allowing the experiment to free-fall in an evacuated tube through a distance of about $150 \mathrm{~m}$. A schematic of the test rack for microgravity tests is shown in Figure 6(a).

The package housed the test rack, containing a wind tunnel, a fuel tray, a fuel delivery syringe, three video cameras, and a gas control system. A fuel tray $(250 \times 20 \mathrm{~mm}$, $3 \mathrm{~mm}$ deep) was located inside the wind tunnel $(7 \times 7 \mathrm{~cm}$, $30 \mathrm{~cm}$ long, Figure $6(\mathrm{~b}))$. The wind tunnel can provide a steady, laminar, forced air flow. The averaged airflow rate is $5 \mathrm{~cm} / \mathrm{s}$. A hot-wire igniter was set up at the end of the tray and $1 \mathrm{~mm}$ above the fuel surface. A thermocouple was inserted in the fuel tray to measure the initial fuel temperature. A top view camera and two side-view cameras recorded the spreading flame. One side-view camera recorded the visible flame and another recorded an ultraviolet image to record the blue flame under microgravity. The test rack was contained in a sealed test package filled with dry air at $1 \mathrm{~atm}$. Once the tray was filled with $24^{\circ} \mathrm{C}$ n-butanol fuel from a fuel delivery system, a $5 \mathrm{~cm} / \mathrm{s}$ airflow opposing the direction of the flame spread was started, and ignition occurred just before the package dropped. The igniter was engaged until a flame appeared.

\section{Results and Discussion}

\subsection{Analytical Results}

Figure 7 shows the critical Ma number versus the thermal subsurface layer depth (defined in Figure 2) with two constant We number cases plotted: We $=1.31$ for normal gravity, and We $=0.89$ for microgravity. The We number is calculated with (22) using the thermal characteristic depth and length of the subsurface layer circulation of [34].

The critical Ma number under microgravity is much larger than that under normal gravity, suggesting that when the liquid surface becomes unstable and a surface wave is formed under microgravity, the value $h_{T}$ will be larger (which means the diameter of subsurface liquid convection will be larger). This possibility, if validated, could explain NASA's microgravity experimental results [16], which showed a large diameter subsurface circulation for $\mathrm{n}$ butanol compared with its normal gravity behavior at the 


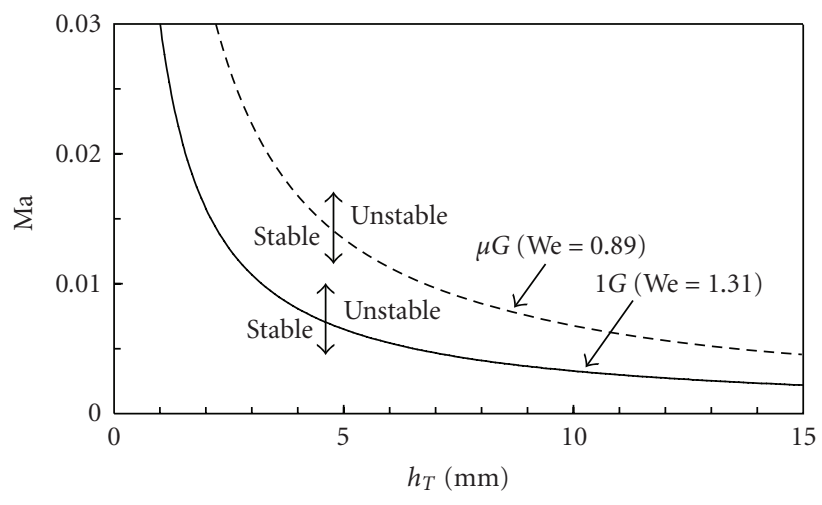

FIgURE 7: Marangoni number versus characteristic depth of subsurface layer circulation.

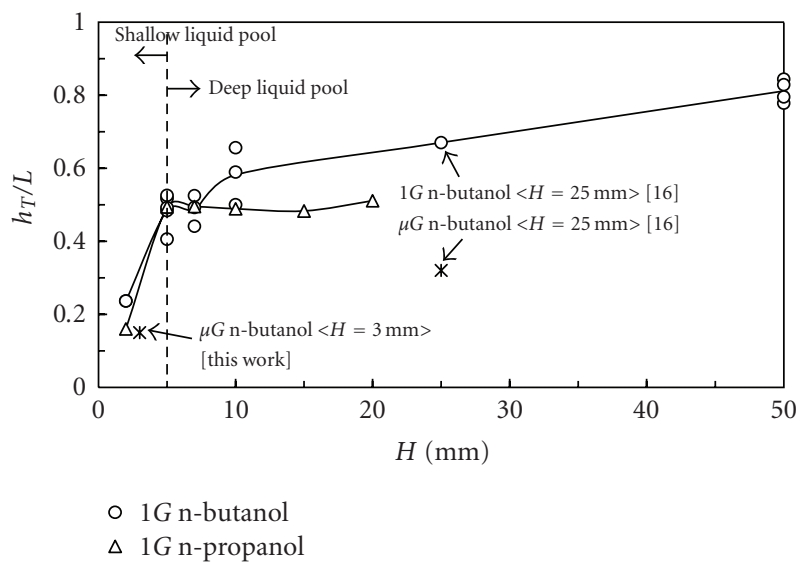

Figure 8: Ratio of characteristic length and characteristic depth of subsurface layer circulation versus initial fuel layer depth (fuel is npropanol and tray width $=20 \mathrm{~mm}$ ).

same temperature. The large subsurface circulation under microgravity takes longer to reach the fully-developed state because gravity is a major contributor to the forces that keep each element of a liquid in communication with its neighbors. This means that the microgravity experiments require a longer tray length to achieve a steady state condition than experiments in normal gravity (which usually employ a 30 to $40 \mathrm{~cm}$ long tray).

\subsection{Thermal and Fluid Scale}

Figure 8 shows the characteristic length scale ratio $h_{T} / L$ as a function of the initial fuel depth $(H)$ for n-propanol and nbutanol, measured by the HSSG technique [34].

The quotient $h_{T} / L$ increased sharply for both n-propanol and n-butanol with increasing initial fuel layer depth in the range $H=2$ to $5 \mathrm{~mm}$ and reached a very slow increase for n-propanol with $H=5$ to $25 \mathrm{~mm}$ and for n-butanol with $H=5$ to $50 \mathrm{~mm}$. This indicates that there are two different regimes with a division at $H=5 \mathrm{~mm}$ : shallow liquid pools for $H<5 \mathrm{~mm}$, and deep liquid pools for $H>5 \mathrm{~mm}$. When

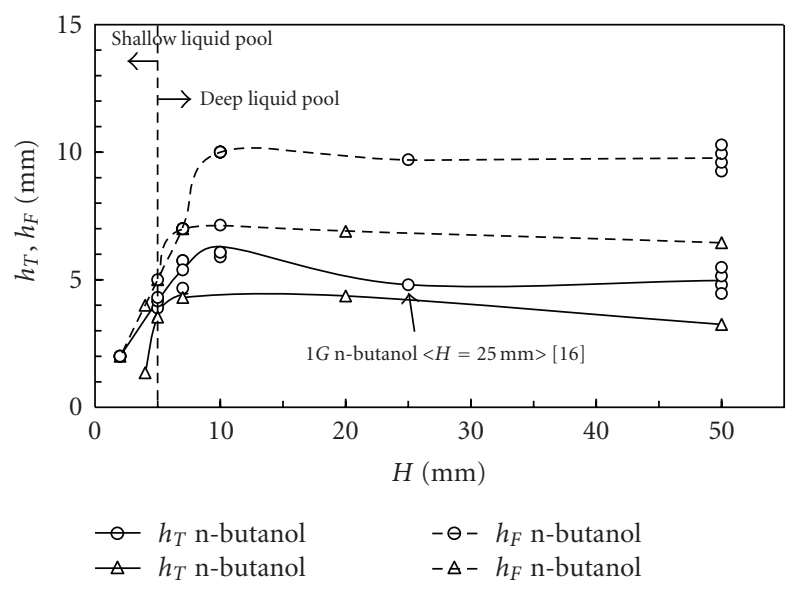

FiguRE 9: Thermal and flow characteristic depth of subsurface layer circulation versus initial fuel layer depth.

the fuel depth is less than $5 \mathrm{~mm}$, the restricted subsurface liquid circulation reduces $h_{T}$ and increases $L$. For an initial fuel depth of $H>5 \mathrm{~mm}$, both the characteristic length $L$ and the circulation depth $h_{T}$ increase with increasing initial fuel depth and reach their constant values, when the deep liquid pool condition is satisfied.

The thermal field is targeted in the experiment, while the theoretical analysis targets the flow field. Therefore, the shadowgraph and PTLS methods were used to measure the thermal scale and the flow scale at the same time. Figure 9 shows $h_{T}$ (thermal characteristic depth) and $h_{F}$ (flow characteristic depth) as functions of the initial fuel layer depth.

The characteristic depth in n-butanol was larger than the depth in n-propanol by a factor of about 1.4. This value is close to the 1.3 ratio of the viscosity coefficients of $n$ propanol and n-butanol. As a result, when a dimensionless number is used, it corrects it by the Prandtl (Pr) number. The Pr number is defined as follows:

$$
\operatorname{Pr}=\frac{v}{a},
$$

where, $v$ is the kinematic viscosity, $a$ is the thermal diffusivity.

\subsection{Scale Analysis of Flame Spread}

The nondimensional flame spread rate may be influenced by the quenching distance $\delta$, associated with the dark region formed between the flame leading edge and the liquid surface, and the diffusivity, $D$, of fuel vapor. A nondimensional form of the flame spread rate, $V / V_{D}$, can therefore be written as follows:

$$
\frac{V}{V_{D}}=\frac{V \delta}{D} .
$$

This nondimensional flame spread $V / V_{D}$ is the same to the vapor Peclet number. We measured the quenching distance at $\delta=0.8 \mathrm{~mm}$ in normal gravity and $\delta=1.2 \mathrm{~mm}$ in microgravity. The diffusivity of fuel vapor, $D$, was calculated from the empirical formula [22] for four different types 


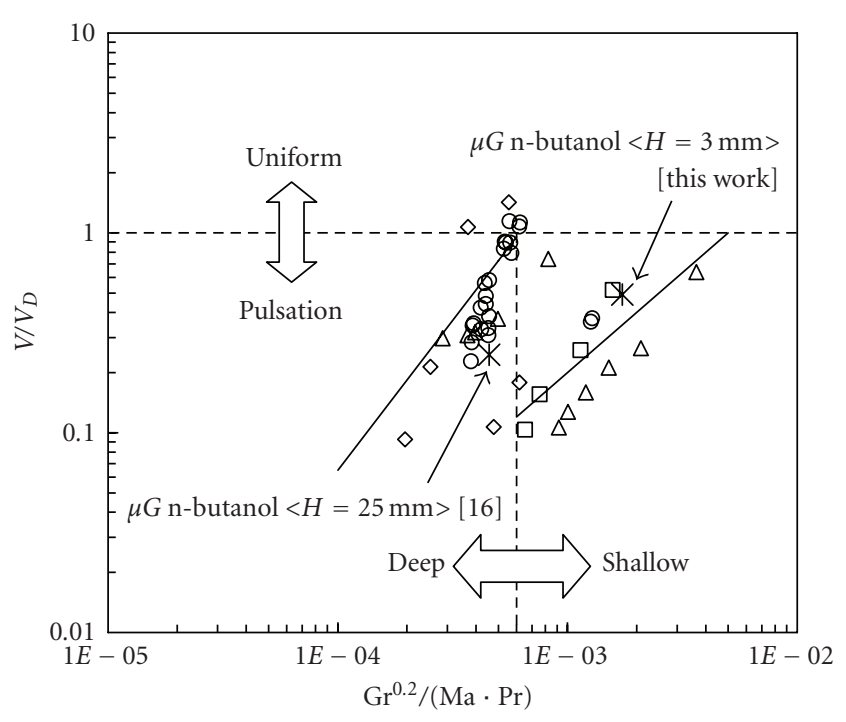

Figure 10: Flame spread rate as a function of for four different alcohols ( $\diamond$ methanol: $H=1-10 \mathrm{~mm}$; $\square$ ethanol: $H=1-5 \mathrm{~mm}$; $\triangle$ n-pripanol: $H=2-20 \mathrm{~mm}$; $\circ$ n-butanol: $H=1-50 \mathrm{~mm}$ ).

of alcohols, $D=1.12 \mathrm{~cm}^{2} / \mathrm{s}$ for ethanol, $D=0.93 \mathrm{~cm}^{2} / \mathrm{s}$ for methanol, $D=0.75 \mathrm{~cm}^{2} / \mathrm{s}$ for n-propanol, and $D=$ $0.63 \mathrm{~cm}^{2} / \mathrm{s}$ for n-butanol.

In a previous scaling analysis [34], the flame spread rate (dimensional) was expressed as a function of $1 / \mathrm{MaPr}$.

$$
\frac{1}{\operatorname{MaPr}}=\frac{4 \mu^{2} a}{\gamma^{2} \rho \sigma_{T} \Delta T v} \frac{1}{h_{T}}\left(\frac{L}{h_{T}}\right)^{2} .
$$

However, 1/ Ma Pr was induced in experimental data, $h_{T}$ and $h_{T} / L$. To improve the scaling analysis, it is thought that the $h_{T}$ and $h_{T} / L$ can be related by combining two nondimensional numbers, $\mathrm{Gr}$ and $\mathrm{Ma}$. The Gr number is related to $h_{T}$, and the Ma number is related to $L$. The experimental data $h_{T}\left(h_{T} / L\right)^{2}$ is expressed as

$$
h_{T}\left(\frac{h_{T}}{L}\right)^{2}=C_{1}\left(\frac{\mathrm{Gr}}{\mathrm{MaPr}}\right)^{c_{2}}=C_{1}\left(\frac{\beta^{2} \rho^{2} g^{2} a}{\sigma_{T} v} h_{T}^{4}\right)^{C_{2}} .
$$

By submitting (10) into (9), we can obtain the following equation:

$$
\frac{\mathrm{Gr}^{-C_{2} /\left(1-C_{2}\right)}}{\operatorname{MaPr}}=\left(\frac{4 C_{1} \mu^{2} a}{\gamma^{2} \rho \sigma_{T} \Delta T v}\right)^{1 /\left(1-C_{2}\right)}
$$

$C_{1}$ and $C_{2}$ are fitted to the experimental data for deep liquid pool: $C_{1}=420, C_{2}=-0.25$.

The time averaged flame spread rates under subflash conditions measured in this study (for four different fuels: methanol, ethanol, n-propanol, and n-butanol) and experimental data from $[12,16]$ are plotted in Figure 10 as a function of $\mathrm{Gr}^{0.2} /(\mathrm{Ma} \cdot \mathrm{Pr})$. The initial fuel depth that produced these data varies from 1 to $50 \mathrm{~mm}$. A clear difference between deep liquid pools $\left(\mathrm{Gr}^{0.2} /(\mathrm{Ma} \cdot \mathrm{Pr})<6 \times\right.$ $\left.10^{-4}\right)$ and shallow liquid pools $\left(\mathrm{Gr}^{0.2} /(\mathrm{Ma} \cdot \mathrm{Pr})>6 \times\right.$ $10^{-4}$ ) can be seen. For deep liquid pools, the flame spread rate correlates with $\left\{\mathrm{Gr}^{0.2} /(\mathrm{Ma} \cdot \mathrm{Pr})\right\}^{1.5}$, while for shallow liquid fuel poolsit correlates with $\left\{\mathrm{Gr}^{0.2} /(\mathrm{Ma} \cdot \mathrm{Pr})\right\}^{1.0}$ in the pulsating flame spread condition. Both the deep and shallow liquid pool regions include microgravity data $(H=3$ and $25 \mathrm{~mm})$.

\section{Conclusions}

Instability and scaling analyses were conducted on experimental data quantifying flame spread over liquid fuels obtained both under normal and microgravity by other researchers and by our group. We arrived at the following conclusions.

(1) We found four important (Ma, Gr, Fr, We) pinumbers and a characteristic length scale ratio, $h_{T} / L$, and used them in a general formula to describe flame spread over liquids. Using this formula, flame spread over liquid was divided into two separate regimes: the shallow-liquid pool and the deep-liquid pool.

(2) The flow and thermal characteristic depths of subsurface circulation were measured by our specially designed high sensitivity shadowgraph (HSSG) combined with a particle-track laser-sheet (PTLS) technique. The flow characteristic depth for n-butanol was twice as deep as the thermal characteristic depth. Based on these experimental results, the characteristic depth scale ratio: $\gamma$ was introduced to compensate for the difference between thermal and fluid subsurface layer depth.

(3) We correlated the nondimensional flame spread rate, $V / V_{D}$, over four different alcohol fuels, the initial fuel depth, and gravity, which ranged from 1 to $50 \mathrm{~mm}$, with $\mathrm{Gr}^{0.2} /(\mathrm{Ma} \cdot \mathrm{Pr})$. The flame spread rate for shallow liquid pools correlates with $\left\{\mathrm{Gr}^{0.2} /(\mathrm{Ma} \cdot \mathrm{Pr})\right\}^{1.0}$, while the spread rate for deep liquid pools correlates with $\left\{\mathrm{Gr}^{0.2} /(\mathrm{Ma} \cdot \mathrm{Pr})\right\}^{1.5}$.

\section{Nomenclature}

A: Amplitude of surface wave, $\mathrm{m}$

A: $\quad$ Thermal diffusivity, $\mathrm{m}^{2} / \mathrm{s}$

$C_{ \pm}: \quad$ Forward and reverse propagation velocities of dynamic wave, $\mathrm{m} / \mathrm{s}$

$C_{0}$ : Propagation velocity of kinematic wave, $\mathrm{m} / \mathrm{s}$

$C: \quad$ Wave velocity, $\mathrm{m} / \mathrm{s}$

D: Diffusion coefficient of fuel vapor, $\mathrm{m}^{2} / \mathrm{s}$

Fr: Froude number

Gr: Grashof number

$g: \quad$ Acceleration due to gravity, $\mathrm{m} / \mathrm{s}^{2}$

$H$ : Initial fuel layer depth, $m$

$h$ : $\quad$ Sub-surface layer depth, $m$

$h_{F}$ : Flow characteristic depth of sub-surface layer circulation, $\mathrm{m}$

$h_{T}$ : Thermal characteristic depth of the sub-surface layer circulation, $\mathrm{m}$

$h_{T} / L$ : Characteristic length scale ratio 
$k$ : $\quad$ Wave number $(\equiv 2 \pi / \lambda), \mathrm{m}^{-1}$

$L$ : Thermal characteristic length of the sub-surface layer circulation, $\mathrm{m}$

Ma: Marangoni number

Pr: Prandtl number

$q_{i}$ : Heat flux from the liquid surface, $\mathrm{W} / \mathrm{m}^{2}$

$T$ : $\quad$ Temperature, $\mathrm{K}$

$T_{b}$ : Liquid bulk temperature, $\mathrm{K}$

$T_{f p}$ : Flash point temperature, $\mathrm{K}$

$U$ : $\quad$ Local liquid velocity $\left(\equiv\left(U_{S} / \bar{h}^{2}\right) y^{2}(0 \leq y \leq \bar{h})\right), \mathrm{m} / \mathrm{s}$

$U_{s}$ : Liquid surface velocity, $\mathrm{m} / \mathrm{s}$

$u$ : Average liquid velocity $\left(\equiv \int_{0}^{\bar{h}} U d y / \bar{h}=(1 / 3) U_{S}\right), \mathrm{m} / \mathrm{s}$

$V: \quad$ Flame spread rate (time averaged), $\mathrm{m} / \mathrm{s}$

$V_{D}$ : Vapor diffusion rate, $\mathrm{m} / \mathrm{s}$

We: Weber number

$x$ : Flow direction coordinate, $\mathrm{m}$

$y: \quad$ Normal direction to the wall, $\mathrm{m}$

\section{Greek Symbols}

$\alpha$ : Heat release factor

$\beta$ : $\quad$ Momentum displacement thickness

$\left(\equiv \int_{0}^{\bar{h}} U^{2} d y / u^{2} \bar{h}=9 / 5\right), \mathrm{m} / \mathrm{s}$

$\gamma$ : Characteristic depth scale ratio $\left(\equiv h_{F} / h_{T}\right)$

$\Delta T$ : Temperature difference between flash point, $T_{f p}$ and liquid bulk temperature, $T_{b}, \mathrm{~K}$

$\delta$ : Quenching distance, $\mathrm{m}$

$\Gamma$ : Liquid volumetric flow rate per unit width of the tray $\left(\equiv \int_{0}^{\bar{h}} U d y=(1 / 3) U_{S} \bar{h}\right), \mathrm{m}^{2} / \mathrm{s}$

$\Gamma_{\mathrm{cr}}$ : Critical flow rate required for surface wave to occur, $\mathrm{m}^{2} / \mathrm{s}$

$\lambda$ : Wavelength, $\mathrm{m}$

$\lambda_{l}$ : Thermal conductivity of the liquid, $\mathrm{W} /(\mathrm{m} \cdot \mathrm{K})$

$v: \quad$ Kinematic viscosity, $\mathrm{m}^{2} / \mathrm{s}$

$\rho:$ Density of the liquid, $\mathrm{kg} / \mathrm{m}^{3}$

$\sigma: \quad$ Surface tension force, $\mathrm{N} / \mathrm{m}$

$\sigma_{T}$ : Temperature derivative of surface tension coefficient, $\mathrm{N} / \mathrm{m} \cdot \mathrm{K}$

$\tau_{b}:$ Shear stress in the liquid, $\mathrm{Pa}$

$\tau_{i}$ : Surface shear stress due to Marangoni effect, $\mathrm{Pa}$

\section{Subscripts}

$\begin{array}{ll}b: & \text { Liquid phase (bulk) } \\ i: & \text { Interface between gas and liquid phase } \\ t: & \text { Partial derivatives in time } \\ x: & \text { Partial derivatives in the } x \text {-direction } \\ \text { Superscript bar: } & \text { Time-averaged quantity } \\ \text { Superscript prime: } & \text { Perturbation quantity. }\end{array}$

\section{Acknowledgments}

This study was supported in part by NASA under Grant NAG3-2567 and in part by the Japan Space Forum on
"Ground-based Research Program for Space Utilization." We would like to thank Dr. K. Kuwana and Dr. F. Miller for valuable technical discussions.

\section{References}

[1] J. H. Burgoyne, A. F. Roberts, and P. G. Quinton, "The spread of flame across a liquid surface-I: the induction period," Proceedings of the Royal Society A, vol. 308, no. 1492, pp. 39-53, 1968.

[2] J. H. Burgoyne and A. F. Roberts, "The spread of flame across a liquid surface-II: steady-state conditions," Proceedings of the Royal Society A, vol. 308, no. 1492, pp. 55-68, 1968.

[3] J. H. Burgoyne and A. F. Roberts, "The spread of flame across a liquid surface-III: a theoretical model," Proceedings of the Royal Society A, vol. 308, no. 1492, pp. 69-79, 1968.

[4] I. Glassman, J. G. Hansel, and T. Eklund, "Hydrodynamic effects in the flame spreading, ignitability and steady burning of liquid fuels," Combustion and Flame, vol. 13, no. 1, pp. 99$101,1969$.

[5] H. Isoda, Kikai no Kenkyu, vol. 23, pp. 1505-1510, 1971.

[6] K. Akita and O. Fujiwara, "Pulsating flame spread along the surface of liquid fuels," Combustion and Flame, vol. 17, no. 2, pp. 268-269, 1971.

[7] K. Akita, "Some problems of flame spread along a liquid surface," Proceedings of the Combustion Institute, vol. 14, no. 1, pp. 1075-1083, 1973.

[8] J. S. Newman, M.S. thesis, Princeton University, Princeton, NJ, USA, 1979.

[9] T. Hirano, T. Suzuki, I. Mashiko, and N. Tanabe, "Gas movements in front of flames propagating across methanol," Combustion Science and Technology, vol. 22, no. 1-2, pp. 8391, 1980.

[10] R. Mackinven, J. G. Hansel, and I. Glassman, "Influence of laboratory parameters on flame spread across liquid fuels," Combustion Science and Technology, vol. 1, no. 4, pp. 293-306, 1970.

[11] Y. Matsumoto and T. Saito, Transactions of the JSME, Series B, vol. 46, pp. 998-1006, 1980.

[12] Y. Matsumoto and T. Saito, Bulletin of JSME, vol. 24, pp. 160 $167,1981$.

[13] I. Glassman and F. L. Dryer, "Flame spreading across liquid fuels," Fire Safety Journal, vol. 3, no. 3, pp. 123-138, 1981.

[14] F. J. Miller and H. D. Ross, Proceedings of the Combustion Institute, vol. 24, pp. 1075-1083, 1992.

[15] F. J. Miller and H. D. Ross, "Further observations of flame spread over laboratory-scale alcohol pools," Proceedings of the Combustion Institute, vol. 24, no. 1, pp. 1703-1711, 1992.

[16] H. D. Ross and F. J. Miller, "Detailed experiments of flame spread across deep butanol pools," Proceedings of the Combustion Institute, vol. 26, no. 1, pp. 1327-1334, 1996.

[17] H. D. Ross, Microgravity Combustion: Fire in Free Fall, chapter 5, Academic Press, San Diego, Calif, USA, 2001.

[18] A. Ito, D. Masuda, and K. Saito, "A study of flame spread over alcohols using holographic interferometry," Combustion and Flame, vol. 83, no. 3-4, pp. 375-389, 1991.

[19] P. L. García-Ybarra, J. C. Antoranz, V. Sankovitch, and J. L. Castillo, "Experimental evidence of self-excited relaxation oscillations leading to homoclinic behavior in spreading flames," Physical Review E, vol. 49, no. 6, pp. 5225-5229, 1994.

[20] H. D. Ross, "Ignition of and flame spread over laboratory-scale pools of pure liquid fuels," Progress in Energy and Combustion Science, vol. 20, no. 1, pp. 17-63, 1994. 
[21] F. J. Miller and H. D. Ross, in Proceedings of the 8th International Symposium on Transport Phenomena in Combustion, San Diego, Calif, USA, July 1995.

[22] T. Hirano and K. Suzuki, "Fire spread phenomena: the role of observation in experiment," Progress in Energy and Combustion Science, vol. 20, no. 6, pp. 461-485, 1995.

[23] P. L. García-Ybarra, J. L. Castillo, J. C. Antoran, V. Sankovitch, and J. San Martin, "Study of the thermocapillary layer preceding slow, steadily spreading flames over liquid fuels," Proceedings of the Combustion Institute, vol. 26, no. 1, pp. 1469-1475, 1996.

[24] F. J. Miller and H. D. Ross, "Smoke visualization of the gas-phase flow during flame spread across a liquid pool," Proceedings of the Combustion Institute, vol. 27, no. 1, pp. 2715-2722, 1998.

[25] H. D. Ross and F. J. Miller, "Flame spread across liquid pools with very low-speed opposed or concurrent airflow," Proceedings of the Combustion Institute, vol. 27, no. 2, pp. 2723-2729, 1998.

[26] A. Ito, A. Narumi, T. Konishi, G. Tashtoush, K. Saito, and C. J. Cremers, "The measurement of transient two-dimensional profiles of velocity and fuel concentration over liquids," Journal of Heat Transfer, vol. 121, no. 2, pp. 413-419, 1999.

[27] A. Ito, T. Konishi, A. Narumi, G. Tashtoush, K. Saito, and C. J. Cramers, in Proceedings of the 5th ASME/JSME Thermal Engineering Joint Conference, San Diego, Calif, USA, March 1999.

[28] T. Konishi, G. Tashtoush, A. Ito, A. Narumi, and K. Saito, "The effect of a cold temperature valley on pulsating flame spread over propanol," Proceedings of the Combustion Institute, vol. 28, no. 2, pp. 2819-2826, 2000

[29] T. Konishi, A. Ito, Y. Kudou, and K. Saito, "The role of a flame-induced liquid surface wave on pulsating flame spread," Proceedings of the Combustion Institute, vol. 29, no. 1, pp. 267272, 2002.

[30] F. A. Williams, Combustion Theory, chapter 1, 2, Benjamin/Cummings, Menlo Park, Calif, USA, 1985.

[31] G. B. Whitham, Linear and Nonlinear Waves, John Wiley \& Sons, New York, NY, USA, 1974.

[32] A. Ito, H. Kawano, and T. Fukano, "Generation of a disturbance wave on a liquid film flowing down a heated inclined plane," JSME International Journal, vol. 35, no. 4, pp. 565-572, 1992.

[33] K. Takahashi, A. Ito, Y. Kudo, T. Konishi, and K. Saito, in Proceedings of the 4th International Symposium on Scale Modeling (ISSM '03), Cleveland, Ohio, USA, September 2003.

[34] K. Takahashi, A. Ito, Y. Kudo, T. Konishi, and K. Saito, "Scaling and instability analyses on flame spread over liquids," Proceedings of the Combustion Institute, vol. 30, no. 2, pp. 2271-2277, 2005. 

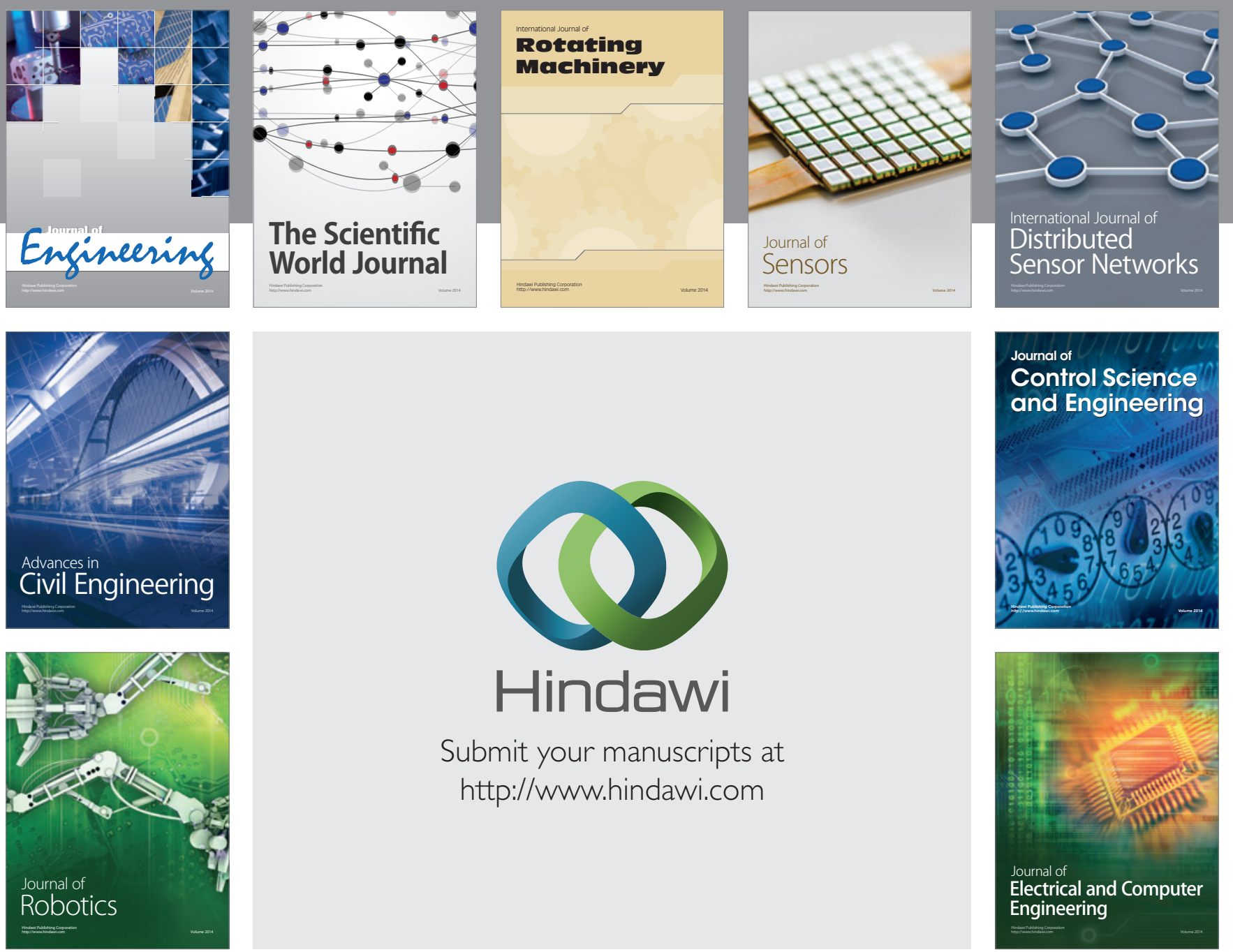

Submit your manuscripts at

http://www.hindawi.com
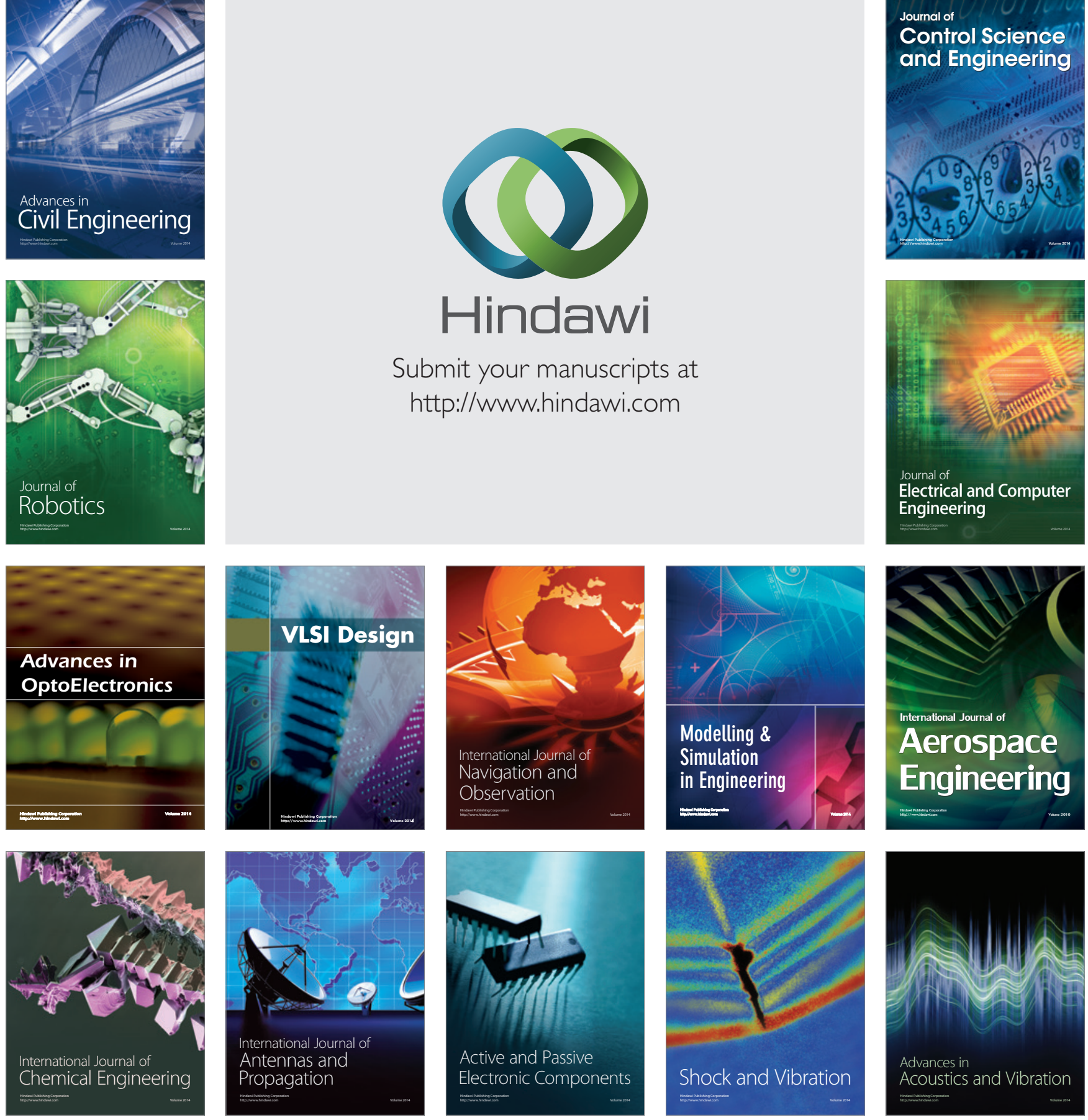